\title{
18. Suggested outline of a living wage report
}

We recommend that living wage reports use a similar outline to the extent possible. In this way, they can be more easily compared. This chapter provides our suggestions for a typical report with explanations of what should be in each section and why.

\section{Background}

This section should be relatively short consisting of one or two paragraphs. It should indicate: (i) area the living wage estimate is estimated for (e.g. rural, urban, city x), including whether it focused on areas near a particular industry (e.g. coffee, tea) or industrial zones; (ii) short description of Anker methodology, its credentials, its past use, and a listing of its main principles in bullet points (e.g. transparency, normative basis, time and place-specific nature, international comparability, practical and modest cost, and consideration of all relevant forms of remuneration); and (iii) organization or organizations that supported the study.

\section{Living Wage Estimate}

This section should indicate the living wage estimate and the month and year of the study so that readers do not have to search through the report to find it. Gross and net living wage should be indicated. A brief indication of the size of gap to prevailing wages or other relevant wage comparators should be provided.

It is useful to indicate in a second paragraph how much effort was put into estimating the living wage such as collection of new information on local costs and use of a range of secondary information, as well as that conservative assumptions were used to estimate the living wage. Such discussion helps give credibility to a living wage report. It is useful to include an Appendix to the report listing sources of information. 


\section{Context}

This section should highlight noteworthy aspects in a country, region, and/or industry that are important to understanding the living wage estimate and so help put it in context. Examples of context discussions in previous living wage reports include the following topics. For the Dominican Republic: the importance of immigrant Haitian workers and the need to earn enough to support a family based on costs in the Dominican Republic and not in Haiti; the importance of small holder farmers. For Malawi: high level of poverty; recent very high inflation rate and currency devaluation; few job opportunities in rural areas and importance of tea estate employment. For Kenya: the fact that flower farm workers live in urban slums surrounding flower farms and not in a rural area; existence of collective bargaining agreement and consequently better working conditions than typical for agriculture; decreasing real wages for workers and increasing cost pressures for flower farms in past decade. For South Africa: recent large increase in legal minimum wage; right to adequate food, water, housing and health care included in South African Constitution; recent living wage campaign by main trade union.

\section{Concept and Definition of a Living Wage}

This section should provide a brief introduction to living wages. It should: (i) cover the concept and idea behind a living wage, (ii) provide the Global Living Wage Coalition (GLWC) definition of a living wage, and (iii) provide historical background and context to living wages. The latter could include quotes such as from human rights conventions, ILO Constitution, historical figures, etc. in the text or in an Appendix. See Chapter 1 in this manual and Anker (2011) for useful quotations.

\section{How a Living Wage is Estimated}

This section should describe the Anker methodology used to estimate the living wage and include Figures 2.1-2.3 for clarity. 


\section{SECTION I. COST OF A BASIC BUT DECENT LIFE FOR A WORKER AND HIS OR HER FAMILY}

\section{Food Costs}

A short introductory paragraph should describe how food costs were estimated using a model diet that is nutritious in more than only calories, low in cost for a nutritious diet, consistent with local food preferences, and based on food prices found in a local market survey. It should then indicate estimated food costs per person per day and per family per month. This paragraph should also indicate that there are three sections concerned with: (i) principles used to develop the model diet, (ii) description of the model diet, and (iii) food prices used to estimate cost of the model diet.

\subsection{General principles of living wage model diet}

This section should indicate the general principles used to establish the model diet (WHO/FAO recommendations as regards calories, proteins, fats, carbohydrates, and fruits and vegetables); consistent with local food preferences; relatively low in cost for a nutritious diet; consistent with development level of country and location; and when possible quantities are expressed in number of portions.

\subsection{Living wage model diet}

This section should describe the living wage model diet including reference to the Excel calorie requirement and model diet programs available on the Edward Elgar website. Discussion should start by indicating how the model diet meets WHO/FAO nutritional standards. This section should also indicate why (and by how much) the cost of the model diet is increased to take into account the need for: variety in the diet, minimal spoilage, and salt/spices/sauces/condiments to make the diet palatable.

Next, the model diet should be described in bullet points using quantities easily understood by laypersons to the extent possible (e.g. two slices of bread, three meat meals per week, one cup of milk per day for children, etc.). Use of bullet points here, helps improve presentation. This should be followed by an indication of noteworthy aspects of the model diet in bullet points. The purpose of this discussion is to make readers aware that food costs for a living wage are as low as possible while meeting nutritional requirements and being consistent with local conditions and local food habits and preferences. The model diet itself should be presented in a table at the end of this section including a comments column with interesting features of the model diet. 
Finally, for countries where other model diets and/or food consumption data are available, it is useful to include a short discussion that compares the living wage model diet with other model diets and/or to food consumption according to secondary data. There could also be discussion comparing the percentage distribution of food expenditure by major food group in the living wage model diet to the percentage distribution of food expenditures according to household survey data. The purpose of such discussions is to indicate that the living wage model diet is reasonable. Therefore, explanations should be provided for major differences.

\subsection{Local food prices}

This section should describe how the food prices used to estimate the cost of the living wage model diet were obtained. Discussion should start by describing how food prices were collected in a local market survey and then go on to indicate in bullet points noteworthy aspects of the selection of food items used to represent major food groups in the living wage model diet. The purpose of this discussion is to indicate that food items were selected in a way to reduce food costs and so help ensure that the cost of the model diet is kept as low as possible for a nutritious diet. There should also be a short discussion about seasonality in food price and any possible adjustments to the food prices collected. Note that including photos of local food markets where workers typically shop is strongly encouraged, because it helps situate readers, especially international readers.

\section{Housing Costs}

An introductory paragraph should indicate that housing costs are estimated by summing up separate estimates of the costs of rent for an acceptable dwelling (or rental equivalent value when owner-occupied dwellings are used because there is little or no rental market), utility costs, and possibly minor repairs and maintenance - and then indicate the estimate of housing costs (rent and utilities) in the location. The introductory paragraph should also discuss how the Anker methodology differs from the usual methodology to measure living wages and poverty lines for developing countries, where all non-food costs (including housing costs) are estimated in one go and why the Anker methodology yields better estimates of the cost of acceptable housing especially in countries where housing conditions are generally poor, as well as in countries where the cost/ value of owner-occupied housing is assumed to be zero in the household expenditure statistics. This paragraph should indicate that this chapter includes sections concerned with: (i) local standard for basic acceptable housing, (ii) rent or user cost of acceptable housing, and (iii) utilities and other costs. 


\subsection{Standard for basic acceptable local housing}

This section should indicate the housing standard for the location and how it was arrived at based on international minimum standards and current local housing conditions. The discussion should start with a description or table that indicates local housing conditions according to recent secondary data (for example, percentage of houses with different types of floors, walls, roof, toilet, water source, electricity, etc.). This discussion should be followed by a listing in bullet points in the text of the local housing standard and how this standard differs from current housing conditions. Discussion should point out how the housing standard is basic and far from being extravagant. Readers should be given a vivid picture of how workers currently live and how basic housing would be even for workers earning a living wage. Including photos in the text of local housing is strongly encouraged - photos of both current housing of workers and basic acceptable housing.

\subsection{Rent or user cost for basic acceptable housing}

This section should indicate how many houses researchers visited, the condition and rent of these houses, and how the researcher estimated the rental cost of local housing using this information. It is important to describe very clearly houses that workers currently live in, rent for these houses, and rent for housing at the local housing standard. Researchers should include a table with information collected such as size (number of rooms and number of square meters), rent, amenities (such as toilet and water source), and comments that describe aspects of each house visited that make it unacceptable or acceptable. Note that for locations where there are few if any rental housing units (such as in many rural areas), it is necessary to estimate the user cost of owned housing that meets the local basic acceptable housing standard by estimating the cost of building and maintaining such a dwelling.

\subsection{Utilities and other housing costs}

This section should indicate how utility costs and other costs such as taxes, fees, and routine maintenance and repairs were estimated. Discussion in this section should also indicate current conditions regarding use of electricity, water, and cooking fuel and if these would differ for workers earning a living wage.

\section{Non-food and Non-housing (NFNH) Costs}

This section should begin with a brief description of the Anker methodology used to estimate non-food non-housing costs (NFNH). The 
second paragraph should indicate the amount estimated for NFNH along with the types of expenditures it covers. The remainder of this section should describe how the NFNH to Food ratio is estimated by taking into consideration: (i) unnecessary expenditures, and (ii) peculiarities of available household expenditure data. A preliminary estimate of NFNH costs is made by multiplying the NFNH to Food ratio by cost of the model diet and then possibly adjusting NFNH based on rapid adjustment post checks. Although not required, it is useful to indicate how the NFNH to Food ratio for the location compares to NFNH to Food ratios for other countries and locations to see how typical or unusual it is.

\section{Post Checks of Non-food and Non-housing Costs}

This section should begin with a brief discussion of how a blind and uncritical use of an extrapolation method to estimate NFNH costs runs the risk of underestimating amounts required for NFNH needs. This section should then indicate that for this reason the costs of acceptable health care and education of children are estimated using rapid assessment methods in order to determine if the amounts for these two human rights included in the preliminary estimate of NFNH costs (from the previous section) are sufficient. The amounts for education and health care are increased when this is necessary according to the post checks discussed in the next two sections.

\subsection{Health care post check}

This subsection should start with a brief description of major health care challenges in the country and location. This should include a discussion of the quality, availability and challenges of government provided health care. This discussion should also indicate the extent to which people use private health care and why. The purpose of this discussion is to establish the extent to which workers would reasonably need money to pay for private health care (and public health care when there are expenses for this). This should be followed by discussion of how frequently people visit public and private health care providers based on secondary data. Rough estimates of cost per visit to each type of provider should be made, based on primary data collected in the location from visits to pharmacies and private clinics and discussion with workers and key informants. Based on this secondary data and primary information, cost of visits to different health care providers (pharmacies, private care, public care) should be estimated and described. The sum of these estimates of likely health care costs should be compared with the amount included for health care in the preliminary NFNH estimate, with an adjustment made to this amount when required. 


\subsection{Education post check}

This section should start with a brief description of the education system in the country and location. This should include an indication of enrollment rates and the availability, quality and challenges of public schooling. This discussion should also indicate the extent to which people use private schools and if by chance this is required for decency. Since education is considered a human right internationally, there should then be a short paragraph indicating that one assumption of the Anker methodology is that children of workers earning a living wage should be able to complete secondary school. This should be followed by discussion about different expenses parents have for school and how much they cost based on discussions with workers and key informants in the location and relevant research papers or other sources of information. The estimated amount needed to educate children through secondary school should be compared with the amount included for education in the preliminary estimate of NFNH costs with an adjustment made to this amount when required. Note that since the amount included for education in the preliminary estimate of NFNH costs is sensitive to how household expenditures for education are classified in national household expenditure statistics, the expenditure classification used for education should be indicated.

\subsection{Possible transportation post check}

This post check should be included in reports when transport is a major expense for families and the sum of percentages of household expenditures for food, housing, education and health care is less than around $60 \%$. This section should start with an indication of amount included for transport in the preliminary estimate of NFNH costs. Discussion should then indicate the proportion of households in the location that own a motorbike or motor vehicle according to household survey data, as well as the distribution of transport expenditures for private vehicles compared to public passenger transport according to household expenditure statistics and CPI expenditure weights. Based on this information and discussions with workers and key informants, it should be explained why it is felt to be reasonable to expect workers earning a living wage to rely exclusively on public passenger transport or to own a private vehicle such as a motorbike. A quick approximate estimate of the cost of transport needs per month for the reference family should then be made by adding up likely costs for common transport costs such as commuting to work, shopping, errands, children's school, doctors, and recreation as well as for visiting extended families once or a few times per year. Note that if ownership of a motorbike is felt to be a local norm, it is necessary to estimate costs of owning and operating a motorbike given 
the number of kilometers of travel expected. The rapid estimate of the cost of transport should then be compared to the amount included for transport in the preliminary estimate of NFNH costs with this increased when required.

\section{Provision for Unexpected Events to Ensure Sustainability}

This section should be short. A brief explanation should be provided of why a small margin is provide for unforeseen events - to help ensure sustainability and help workers avoid getting into a downward debt cycle. The percentage used to calculate this $(5 \%)$ should be indicated along with the amount in local currency. In countries where extended family obligations are especially strong and a researcher feels it is warranted to include additional funds for these obligations (usually $5 \%$ ), this should be indicated and justified in the text.

\section{SECTION II. LIVING WAGE FOR WORKERS}

\section{Family Size Needing to be Supported by Living Wage}

This section should indicate that living wage is a family concept and therefore that it is necessary to determine an appropriate reference family size for the location. This section should indicate the reference family size and how it was determined, and why it is a reasonable family size for estimating a living wage for the country/location. Note that it is useful to include information on average household size from several sources because average household size from surveys and censuses is sensitive to how households are defined and measured.

\section{Number of Full-time Equivalent Workers in Family Providing Support}

This section should start by indicating that since living wage is a family concept, there is more than one full-time worker in the reference size family, but less than two full-time workers because of voluntary inactivity, unemployment and part-time work. Discussion should then describe how the number of full-time workers per couple used to estimate the living wage was estimated using labor force participation rates, unemployment rates, and part-time employment rates for the location and appropriate age group. This discussion should include information on each of these factors from several data sources when possible along with a critical appraisal of 
these data to explain and justify how the number of full-time workers per couple was determined.

\section{Take Home Pay Required and Taking Taxes and Statutory Deductions from Pay into Account}

Up to this point, a living wage report would have been concerned with how much take home pay a worker needs to be able to afford a basic but decent standard of living for his/her family. This section should start by indicating that it is necessary to take into consideration income tax and statutory deductions from pay to ensure sufficient take home pay and sufficient disposable income for workers to be able to afford a decent standard of living for themselves and their family. This discussion should indicate all statutory payroll deductions along with their percentages or amounts, whichever applies.

\section{SECTION III. ESTIMATING GAPS BETWEEN LIVING WAGE AND PREVAILING WAGES}

\section{Prevailing Wages (for Industry or Establishment when Living Wage Study is Done for Company or Certifying Organization)}

One important reason for estimating a living wage is to determine if workers receive a living wage and if employers pay a living wage. This section should indicate prevailing wages in a country for different occupations and industries. Prevailing wages should also be indicated for an industry or establishment of interest when a living wage study is funded by a company or certifying/standards organization. Discussion should start with an indication of: (i) the types/major groups of workers being considered, and (ii) the general principles used to determine which forms of remuneration (e.g. base pay, overtime, production bonuses, cash allowances, in kind benefits, and fringe benefits) should be included in current wages for purposes of comparing them to a living wage and thereby determining the gap between current wages and a living wage.

\subsection{Basic wage, cash allowances and bonuses, and overtime pay}

Common forms and amounts of remuneration in the industry or establishment of interest should be listed along with an indication of whether or not each is appropriate for inclusion in wages for comparison to a living wage. This naturally leads to an estimate of remuneration in the industry 
or establishment of interest that is appropriate to compare with living wage. This discussion and results should be provided for major types of workers in the industry or establishment of interest (e.g. tea plucker, fieldworker, and factory worker for tea plantations; grades 4-7 for garment workers in Bangladesh).

\subsection{In kind benefits as partial payment of living wage}

Since in kind benefits provided by employers can reduce the amount of cash wage required to ensure that workers earn a living wage, this section should estimate fair and reasonable monetary values for in kind benefits when a living wage study focuses on a particular industry or establishment. In this way, a more complete picture of prevailing wages in an industry or establishment is provided and therefore more realistic estimates of gaps between prevailing wages and a living wage. Note that this section can sometimes be fairly long because of the controversy often surrounding in kind benefits. Discussion should start with a brief explanation of why in kind benefits can be valuable to workers along with a list of typical in kind benefits provided in the industry or establishment of focus. This should be followed by discussion of the general principles and guidelines used to determine which in kind benefits are appropriate to include as partial payment of a living wage as well as how to estimate fair and reasonable values for them. Next, in a series of subsections each in kind benefit provided should be described and valued in a critical and transparent manner using the already indicated principles and guidelines. Finally, a short subsection should draw together results for all of the individual in kind benefits.

\section{Living Wage in Context and Compared with Other Wages}

\subsection{Wage ladder}

It is important to put a living wage estimate into context by comparing it with other wage indicators - so that gaps between the living wage and other wages can be determined such as to minimum wage, poverty line wages, and various prevailing wages. This should be done in a wage ladder where the living wage estimate and other wage indicators are displayed visually next to each other. Observed wage gaps should be discussed in the text based on this wage ladder figure.

\subsection{Recent wage trends}

When possible, it is informative to include figures and discussion on recent trends in wages, labor costs and labor productivity, because this provides an important context for understanding pressures on workers and 
employers. A situation where real wages have fallen in recent years represents quite a different context and pressure for workers compared with a situation where real wages have risen substantially in recent years, regardless of the current gap between prevailing wages and living wage.

\section{Conclusions}

This section should provide a summary as well as indicate important conclusions. It is important for the conclusions section to be well written and convincing, because many readers only look at a conclusions section. This section should start by indicating the estimated net and gross living wages, so that readers can immediately know the living wage. This section should include summary tables that indicate how the living wage was estimated (see Chapter 19). Discussion should indicate gaps between prevailing wages and the living wage. This discussion should provide additional information on these gaps when a living wage study focused on a particular industry. Next, discussion should emphasize and illustrate how the living wage is a conservative estimate of how much is needed for decency. Such discussion is important so that readers are not left with the impression that the living wage is an exaggerated and utopian estimate of needs. This should be done using examples of some of the conservative assumptions that were used to estimate the living wage and therefore the basic level of living that is affordable on the living wage estimate. It is also often useful to point out interesting aspects of local living conditions, recent wage trends and possibly increased pressure on workers, and the extent to which employers and actors higher up the value chain may be in a position to help raise wages and so move wages toward a living wage. It is often useful to end by indicating how much effort was put into estimating the living wage so that readers are aware of how seriously estimation of a living wage was taken.

\section{References}

A complete list of references should be included at the end of the text. 